\title{
Métodos de inoculação de Rhizoctonia solani e Macrophomina phaseolina em meloeiro (Cucumis melo)
}

\author{
Alexis Calafange Medeiros ${ }^{1}$; Dalila Regina Mota de $\mathrm{Melo}^{2}$; Márcia Michelle de Queiroz Ambrósio3; Glauber \\ Henrique de Sousa Nunes ${ }^{3}$; José Maria da Costa ${ }^{4}$.
}

\begin{abstract}
${ }^{1}$ Mestre em Fitotecnia, Universidade Federal Rural do Semiárido - Av. Francisco Mota, 572, Bairro Costa e Silva - Mossoró-RN, CEP: 59.625900. ecoclafange@hotmail.com; ${ }^{2}$ Doutora em Fitotecnia, Universidade Estadual da Paraíba - Campus IV - Sitio Cajueiro, S/N, Zona Rural, Catolé do Rocha - PB, CEP: 58884-000. ${ }^{3}$ Professor (a) do Departamento de Ciências Vegetais da Universidade Federal Rural do Semiárido Av. Francisco Mota, 572, Bairro Costa e Silva - Mossoró-RN, CEP: 59.625-900, marciamichelle@ufersa.edu.br, glauber@ufersa.edu.br; ${ }^{4}$ Doutorando em Fitotecnia, Universidade Federal Rural do Semiárido - Av. Francisco Mota, 572, Bairro Costa e Silva - Mossoró-RN, CEP: 59.625-900. jmc. atm@hotmail.com.

Autor para correspondência: Dalila Regina Mota de Melo (dalilaregina @hotmail.com)

Data de chegada: 06/03/2015. Aceito para publicação em: 10/09/2015.
\end{abstract}

$10.1590 / 0100-5405 / 2083$

\section{RESUMO}

Medeiros, A.C.; Melo, D.R.M.; Ambrósio, M.M.Q.; Nunes, G.H.S.; Costa, J.M.. Métodos de inoculação de Rhizoctonia solani e Macrophomina phaseolina em meloeiro (Cucumis melo). Summa Phytopathologica, v.41, n.4, p.281-286, 2015.

A utilização de métodos de inoculação constitui uma medida estratégica no estudo de resistência das cucurbitáceas. O objetivo deste trabalho foi avaliar dois métodos de inoculação de Rhizoctonia solani e Macrophomina phaseolina em meloeiro, visando o estudo de resistência. O experimento foi conduzido em casa de vegetação na Universidade Federal Rural do Semiárido, em Mossoró-RN, Brasil. Foram avaliados 05 acessos: A-09, A-16, A-18, A-22 e A-33 para $R$. solani e A-09, A-16, A-24, MR-1 e 'Olimpic' para M. phaseolina. Foram estudados os métodos areno-orgânico e palito de dente. Utilizou-se o delineamento inteiramente casualizado, com 5 repetições. Os isolados utilizados foram: Me 242, Me 243, Me 244 de $R$. Solani e I-248, I-249 e I-250 de M. phaseolina. Os acessos de meloeiro foram avaliados quanto à severidade da doença por uma escala de nota de 1 a 5 . O método do palito de dente foi o mais eficiente em discriminar acessos de melão resistentes e suscetíveis e os isolados de $R$. solani e M. phaseolina quanto à virulência.

Palavras-chave: Melão, patógenos de solo, resistência.

\section{ABSTRACT}

Medeiros, A.C.; Melo, D.R.M.; Ambrósio, M.M.Q.; Nunes, G.H.S.; Costa, J.M.. Methods of inoculation of Rhizoctonia solani and Macrophomina phaseolina in melon (Cucumis melo). Summa Phytopathologica, v.41, n.4, p.281-286, 2015.

The use of inoculation methods is a strategic measure in the study of cucurbits resistance. The aim of this study was to evaluate two methods of inoculation of Rhizoctonia solani and Macrophomina phaseolina in melon, focusing resistance. The experiment was conducted in a greenhouse at the Rural Federal University of the Semi-arid, in Mossoró - RN, Brazil. Five accessions were evaluated: A-09, A-16, A-18, A-22 and A-33 for R. solani and A-09, A-16, A-24, MR-1 and 'Olympic' for M. phaseolina. The studied methods were sandy-organic and toothpick. A completely randomized design was adopted, including five replicates. The used isolates were: Me 242, Me 243, Me 244 of $R$. solani and I-248, I-249 and I-250 of M. phaseolina. Melon accessions were evaluated for disease severity by means of a score scale from 1 to 5 . The toothpick method was the most efficient in discriminating between resistant and susceptible melon accessions and $R$. solani and $M$. phaseolina isolates for virulence.

Additional key-words: Melon, soil borne pathogens, resistance.

A cultura do meloeiro tem grande expressão econômica no Brasil onde as condições geográficas, edáficas e climáticas são favoráveis à exploração tecnológica intensa, visando principalmente o mercado externo. O cultivo intenso do melão no Nordeste brasileiro tem contribuído para o aumento na incidência e severidade de diversas doenças, dentre elas, as causadas por patógenos habitantes do solo, causando perdas econômicas para os produtores da região (17).

Dentre os problemas fitossanitários destaca-se a Rizoctoniose do meloeiro, causada por Rhizoctonia solani Kuhn (3), a qual vem se destacando com o aumento de incidência e severidade. As plantas infectadas com esse patógeno apresentam sintomas de podridão de sementes, morte de plântulas, cancro nos talos, podridão de raízes, tendo como consequência a morte prematura da planta e/ou a redução da produtividade $(5,10)$.
Outro destaque é o denominado "colapso das ramas", que é decorrente do desequilíbrio hídrico entre o sistema radicular e a parte aérea da planta, principalmente no estádio próximo à colheita, devido ao apodrecimento do sistema radicular (9). Muitos patógenos habitantes do solo, atuando de forma isolada ou conjunta, estão associados a essa doença, dentre eles está o fungo Macrophomina phaseolina Tassi (Goid.). Este patógeno tem sido isolado de raízes de meloeiro e de plantas daninhas prevalentes (3).

A utilização de cultivares resistentes constitui uma medida estratégica no manejo integrado de doenças, porém, apesar de sua relevância, existem poucos estudos sobre a avaliação da resistência de meloeiro aos fitopatógenos em questão. Algumas pesquisas buscaram a obtenção de fontes de resistência a Rhizoctonia solani em acessos e cultivares comerciais de melão $(6,19,21)$ e, segundo os autores, fontes 
promissoras de resistência para futuros programas de melhoramento foram encontradas nessas pesquisas. Salari et al. (23) avaliando 18 cultivares a um isolado de $M$. phaseolina, identificaram os cultivares 'Sfidak khatdar' e 'Sfidak bekhat' como moderadamente resistentes.

Ao se avaliar germoplasma em busca de fontes de resistência a doenças, métodos eficientes de infecção uniforme das plântulas com isolados patogênicos e virulentos do patógeno são requisitos essenciais. Alguns métodos de inoculação, em condições controladas, têm sido empregados com sucesso em diversas culturas $(6,27)$.

Nesse processo é fundamental o desenvolvimento e a padronização de metodologias que permitam a seleção segura dessas fontes de resistência e a determinação precisa da reação, de resistência ou suscetibilidade dos genótipos avaliados. Na tentativa de multiplicar $R$. solani artificialmente, o inóculo é cultivado em substratos como arroz $(6,20)$, aveia $(11)$, areno-orgânico $(8,19)$, palito $(28)$ e outros que apresentam diferentes tempos para colonização, secagem, armazenagem e viabilidade do inóculo. Os estudos também apresentam modificações na forma como o solo foi infestado, diferindo nas densidades e na distância do inóculo à semente (20).

Para inoculação de M. phaseolina, o método do palito tem sido o mais indicado em beterraba (16) e sorgo (13). No caso do meloeiro, o método foi utilizado com sucesso para avaliar a reação a Didymella bryoniae, em diversas cucurbitáceas candidatas a porta-enxertos de melão rendilhado (12). $\mathrm{O}$ método de inoculação com discos de meio de cultura, contendo estruturas do patógeno no colo da planta foi utilizado com sucesso por Salari et al. (23) na avaliação de cultivares ao referido fungo.

Em face da importância da cultura para o Nordeste brasileiro e das perdas de produção inerentes ao ataque destes fitopatógenos causadores de podridões radiculares, com a hipótese testar a eficiência do método do palito de dente na avaliação de genótipos de melão a doenças, este trabalho teve como objetivo avaliar dois métodos de inoculação de Rhizoctonia solani e Macrophomina phaseolina em meloeiro.

\section{MATERIAL E MÉTODOS}

Os experimentos foram conduzidos em Casa de Vegetação e no laboratório de Microbiologia e Fitopatologia da Universidade Federal Rural do Semi-Árido (UFERSA) no município de Mossoró-RN, Brasil, no período de dezembro de 2011 a novembro de 2012.

O trabalho consistiu de três experimentos testando os patógenos, isolados e duas metodologias de inoculação. Todos os trabalhos foram realizados no mesmo local. Os métodos de inoculação utilizados foram substrato areno-orgânico e palito de dente, ambos infectados com os patógenos.

Foram utilizados os genótipos de melão do Banco de Germoplasma de Cucurbitáceas da UFERSA: A-09, A-16, A-18, A-22 e A-33 para $R$. solani e os acessos A-09, A-16, A-24, MR-1 e 'Olimpic' para $M$. phaseolina. As sementes foram submetidas a um processo de seleção, onde foram descartadas as que apresentaram algum dano como rachaduras, furos, etc. Posteriormente, foram desinfestadas com $\mathrm{NaClO}$ a $1,5 \%$ por dois minutos (21), lavadas em água corrente e postas para secar sobre papel absorvente por 24 horas em temperatura ambiente $\left( \pm 28^{\circ} \mathrm{C}\right)$. Este processo foi realizado em cada acesso separadamente.

Foram utilizados três isolados de R. solani, Me-242, Me-243 e Me244 , todos coletados de melão amarelo infectados com sintomas de podridão de raiz e colo e, com o teste de patogenicidade comprovado. $\mathrm{O}$ Me 242 foi proveniente de uma área produtora de melão da empresa Agrícola Famosa e os isolados Me 243 e Me 244 foram coletados em épocas e locais diferentes na horta didática da UFERSA. Estes apresentam micélios com colorações distintas.

Os três isolados de M. phaseolina foram obtidos de raízes e colos de meloeiro, com sintomas de podridão radicular, proveniente de campos de produção de melão do Agropólo Mossoró-Assú, codificados como Me -248, Me -249 e Me -250. O Me -248 foi proveniente de área produtora de melão em Mossoró-RN. Me -249 foi coletado na horta didática da UFERSA e o isolado Me-250 foi proveniente de uma área produtora de melão da empresa Agrícola Famosa, localizada em Icapuí-CE.

Os isolados estão depositados e preservados na coleção de culturas de fungos do laboratório de Fitopatologia do setor de Fitossanidade da UFERSA.

Para o método de inoculação usando substrato areno-orgânico, a multiplicação dos isolados foi realizada repicando-se separadamente os fungos, para placas de Petri contendo meio de cultura Batata Dextrose Ágar (BDA) + tetraciclina $(0,05 \mathrm{~g} / \mathrm{L})$ e incubados por cinco dias a $28 \pm$ $2{ }^{\circ} \mathrm{C}$, em estufa tipo B.O.D. (Biochemistry Oxigen Demand).

O inóculo de cada isolado foi cultivado em frascos, contendo substrato areno-orgânico (16) composto de três partes de esterco curtido, uma parte de areia lavada e $2 \%$ de aveia (v/p), após o preparo desta mistura, foram adicionados $20 \mathrm{~mL}$ de água destilada para cada $100 \mathrm{~mL}$ de substrato. Este substrato foi autoclavado duas vezes, em intervalos de 24 horas, durante uma hora a $120^{\circ} \mathrm{C}$.

Em câmara asséptica, foram transferidos três discos de $5 \mathrm{~mm}$ de diâmetro retirados das bordas das colônias dos isolados de $R$. solani, para os frascos contendo o substrato areno-orgânico devidamente esterilizado. Esses foram mantidos em estufa tipo B.O.D. a $28 \pm 2^{\circ} \mathrm{C}$, no escuro, por quinze dias, sendo periodicamente agitados com o objetivo de homogeneizar a infestação; também foi mantido um frasco sem o fungo, nas mesmas condições dos frascos contendo as estruturas do patógeno, servindo como testemunha de possíveis contaminações.

A infestação do solo ocorreu no dia da semeadura, pela distribuição homogênea do inóculo do fungo até $10 \mathrm{~cm}$ de profundidade, na proporção de $3 \%$ da capacidade do vaso $(0,4 \mathrm{~kg})(8)$. Para termo de comparação foi deixado à testemunha sem o inóculo.

Para o método de inoculação usando palito de dente infestado, os isolados foram previamente repicados, separadamente, para meio de cultura Batata Dextrose Ágar (BDA) + tetraciclina $(0,05 \mathrm{~g} / \mathrm{L})$ e mantidos em estufa tipo B.O.D. a $28 \pm 2^{\circ} \mathrm{C}$ por 7 dias até serem usados no preparo do inóculo.

No preparo do inóculo foram utilizadas pontas de palitos de dente $(1,5 \mathrm{~cm})$, inseridas verticalmente em um disco de papel filtro com o mesmo diâmetro interno da placa de Petri. Depois de colocados dentro das placas, com a parte afilada dos palitos voltada para cima, estes foram esterilizados a $121{ }^{\circ} \mathrm{C} \mathrm{em}$ autoclave, por 30 minutos (30).

Posteriormente, verteu-se meio de cultivo BDA deixando expostos cerca de $2 \mathrm{~mm}$ da extremidade dos palitos. Após a solidificação do meio de cultura, foram repicados três discos de $0,5 \mathrm{~mm}$ de diâmetro com estruturas do fungo (micélio), distribuídos equidistantes e incubados por cerca de oito dias, em estufa tipo B.O.D a $28 \pm 2^{\circ} \mathrm{C}$ para a completa colonização dos palitos.

Por ocasião da inoculação, os palitos estavam com suas extremidades totalmente colonizadas pelo fungo. Esta ocorreu aos 15 dias após a semeadura, onde os palitos colonizados com o fungo foram inseridos no colo da planta, na altura de $\pm 0,05 \mathrm{~mm}$ do solo. Os palitos sem o inóculo, também esterilizado em autoclave, foram utilizados como controle (testemunha).

Foram semeadas três sementes em vaso plástico com $0,4 \mathrm{~kg}$ de capacidade, sendo mantida uma planta após o desbaste, estes contendo 
uma mistura de solo e substrato comercial. O solo utilizado foi arenoargiloso, classificado como Argissolo Vermelho Amarelo, coletado na própria Instituição, sendo este comum nas fazendas produtoras de meloeiro, previamente desinfestado a $100^{\circ} \mathrm{C}$, durante quatro horas em forno.

O substrato utilizado foi o Tropstrato HT Hortaliças nos experimentos com $R$. solani e fibra de coco (vida verde ${ }^{\circledR}$ ) para $M$. phaseolina, numa proporção de 2:1 (Duas quantidades de solo e uma de substrato). A mistura solo + substrato foi devidamente esterilizada em autoclave a $121^{\circ} \mathrm{C}$, por dois dias consecutivos, sendo uma hora por dia. Posteriormente, foram infestados, de acordo com o método a ser testado, com os isolados do fungo previamente multiplicados, conforme citado anteriormente. Foram semeadas três sementes por vaso, sendo mantida uma planta após o desbaste, realizado 10 dias após o plantio.

Em ambos os experimento os acessos foram avaliados quanto à incidência e severidade da doença, trinta dias após a inoculação, no método que utilizou substrato areno-orgânico e, cinco dias no método do palito. A escala de notas adotada foi a de Noronha et al. (22), adaptada, onde 0 : ausência de sintomas; 1 : hipocótilo com pequenas lesões; 2 : hipocótilo com grandes lesões sem constrição; 3 : hipocótilo totalmente constrito, mostrando tombamento; e 4: sementes não germinadas e/ou plântulas não emergidas.

A severidade média da doença foi utilizada para agrupar os acessos em classes de resistência. A associação da classe de resistência com a nota da escala diagramática foi feita da seguinte forma, 0 : imune; 0,1 a 1,0: altamente resistente; 1,1 a 2,0: moderadamente resistente; 2,1 a 3,0: suscetível e 3,1 a 4,0: altamente suscetível (22).

Depois de realizada a avaliação, em ambos os experimentos, as plantas que obtiveram notas diferentes de zero, foram levadas para o Laboratório para confirmar a presença do fungo nas lesões. Para isso, foram efetuados pequenos cortes na região de transição da lesão e procedeu-se a desinfestação superficial em álcool 70\% durante 30 segundos e em hipoclorito de sódio a 2,0\% por um minuto, sendo em seguida lavados em água destilada esterilizada (ADE). O procedimento foi realizado em câmara de fluxo laminar. Os fragmentos desinfestados foram plaqueados em meio de cultura BDA + tetraciclina $(0,05 \mathrm{~g} / \mathrm{L})$. Assim, foi confirmada a identidade do fungo pela sua caracterização morfológica in vitro.

O delineamento utilizado nos experimentos foi o inteiramente casualizado, com 5 repetições. A unidade experimental foi constituída de um vaso plástico com $0,4 \mathrm{~kg}$ de capacidade, com uma planta. Os vasos foram mantidos em casa de vegetação com temperatura média de $33{ }^{\circ} \mathrm{C}$ e irrigação diária por aspersão com três turnos de rega, 10 minutos cada.

As análises estatísticas foram realizadas pela macro SAS F1_LD_F1 para realizar a análise de variância (ATS) que testou o efeito de métodos de inoculação, acessos e a interação entre os fatores. As estimativas do efeito relativo de tratamentos e ordenamento médio (Rank médio) foram obtidas pelas macro LD_CI. As macros foram obtidas no website do Professor Edgard Brunner da Universidade de Gotting $(<\mathrm{http}: / /$ www. ams.med.uni-goettingen.de/de/sof/ld/makros.html>). A descrição das análises realizadas no presente trabalho está detalhada no artigo de Shan e Madden (25). Em todas as análises foram utilizadas o nível nominal de significância de $5 \%$ de probabilidade $(\alpha=0,05)$.

\section{RESULTADOS E DISCUSSÃO}

Com relação aos métodos de inoculação, ficou evidente a diferença entre as duas formas de inocular o fungo em meloeiro com relação à severidade. O método do palito foi mais eficiente para discriminar os acessos para doenças, independentemente do isolado utilizado na inoculação (Tabelas 1, 2 e 3). Uma provável explicação está no fato da metodologia de infestar o solo com o patógeno ser menos severa e exigir maior período de tempo para o surgimento de sintomas, uma vez que o patógeno precisa se estabelecer no solo para poder colonizar e efetuar a infecção.

Bruton e Wann (4) comentam que em cucurbitáceas trepadoras, a podridão das raízes causadas por $R$. solani e $M$. phaseolina coincide com a senescência da planta. Como consequência, a aplicação do substrato areno-orgânico para avaliar um grande número de acessos teria como principais desvantagens o maior tempo para avaliação e a maior quantidade de solo, uma vez que recipientes maiores seriam necessários para que a planta atingisse a senescência.

No método do palito, o patógeno é introduzido no tecido vegetal, facilitando a infecção e a colonização dos tecidos, expressão de sintomas e discriminação da resistência dos acessos aos patógenos.

A severidade causada pelos isolados, inoculados por meio do método do palito permitiu a discriminação de materiais em várias classes de reação, o mesmo não foi observado no método no qual se utilizou o substrato areno-orgânico (Tabelas 2 e 3). Tomando-se a perspectiva do melhorista de plantas, pode-se afirmar que o método do palito foi mais eficiente na identificação de fontes de resistência e diferenciar genótipos resistentes e suscetíveis em função da virulência do isolado do patógeno.

O método do palito foi capaz de evidenciar a heterogeneidade fitopatogênica dos isolados utilizados no presente estudo (Tabelas 2 e 3 ).

$\mathrm{O}$ conhecimento da variabilidade fitopatogênica é fundamental porque permite o estudo da estabilidade da resistência de genótipos do hospedeiro frente aos isolados do patógeno. Por outro lado, a falta de informações sobre a estrutura populacional do patógeno é um dos fatores limitantes para o sucesso de um programa, uma vez que não permite o estudo de uma possível interação entre genótipos e isolados (16).

De uma forma mais prática, o conhecimento da variabilidade do patógeno interfere na identificação de fontes de resistência no hospedeiro. Pelos resultados observados, constata-se variabilidade entre os isolados quando se empregou o método de inoculação do palito.

A variabilidade fitopatôgenica em $R$. solani e M. phaseolina foi relatada no Brasil por Almeida et al. (1) em isolados originários de

Tabela 1. Valor de F obtidos conforme análise de variância (ATS) não paramétrica para severidade avaliada em acessos de meloeiro inoculados com diferentes isolados de genótipos de R. solani e M. phaseolina. Mossoró-RN, 2013.

\begin{tabular}{|c|c|c|c|c|c|c|}
\hline \multirow[t]{2}{*}{ FV } & \multicolumn{6}{|c|}{ Anova - $(\text { ATS })^{1}$} \\
\hline & \multicolumn{3}{|c|}{ Isolados - R. solani } & \multicolumn{3}{|c|}{ Isolados - M. phaseolina } \\
\hline Métodos & $18,12^{* *}$ & $30,78^{* *}$ & $26,67^{* *}$ & $323,41^{* *}$ & $28,86^{* *}$ & $32,92^{* *}$ \\
\hline $\mathrm{A} \times \mathrm{M}$ & $2,91^{*}$ & $2,87^{*}$ & $2,75^{*}$ & $5,98^{* *}$ & $2,46^{*}$ & $2,30^{*}$ \\
\hline
\end{tabular}

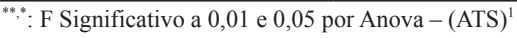


Tabela 2. Nota média e reação de acessos de meloeiro a três isolados de $R$. solani inoculados pelo método do substrato areno-orgânico e do palito. Mossoró-RN, UFERSA, 2013.

\begin{tabular}{|c|c|c|c|c|c|c|}
\hline \multicolumn{7}{|c|}{ Método do substrato areno-orgânico } \\
\hline \multirow{2}{*}{ Acesso } & \multicolumn{2}{|c|}{ Me 242} & \multicolumn{2}{|c|}{ Me 243} & \multicolumn{2}{|c|}{ Me 244} \\
\hline & Média & Reação & Média & Reação & Média & Reação \\
\hline A-09 & 0,6 & MR & 0 & I & 0 & I \\
\hline A-16 & 0 & I & 0,25 & MR & 0 & I \\
\hline A-18 & 0,4 & MR & 0 & I & 0,4 & MR \\
\hline A-22 & 0 & I & 0 & $\mathrm{I}$ & 0 & I \\
\hline A-33 & 0,6 & MR & 0 & I & 0,4 & MR \\
\hline \multicolumn{7}{|c|}{ Método do palito } \\
\hline A-09 & 1,4 & MR & 3,0 & $\mathrm{~S}$ & 2,4 & $\mathrm{~S}$ \\
\hline A-16 & 2,6 & $\mathrm{~S}$ & 1,8 & MR & 1,8 & AR \\
\hline A-18 & 2,2 & $\mathrm{~S}$ & 3,0 & $\mathrm{~S}$ & 3,0 & $\mathrm{~S}$ \\
\hline A-22 & 1,6 & MR & 2,0 & MR & 3.0 & $\mathrm{~S}$ \\
\hline A-33 & 3.0 & $\mathrm{~S}$ & 3,0 & $\mathrm{~S}$ & 3,0 & $\mathrm{~S}$ \\
\hline
\end{tabular}

Significativo pelo teste de Kruskal-Wallis a 1\% de probabilidade. I: Imune [0,0]; AR: altamente resistente [0,1-1,0]; MR: medianamente resistente [1,1-2,0]; S: suscetível [2,1-3,0]; AS: altamente suscetível $[3,1-4,0]$.

Tabela 3. Nota média e reação de acessos de meloeiro a três isolados de M. phaseolina inoculados pelo método do substrato areno-orgânico e do palito. Mossoró-RN, UFERSA, 2013.

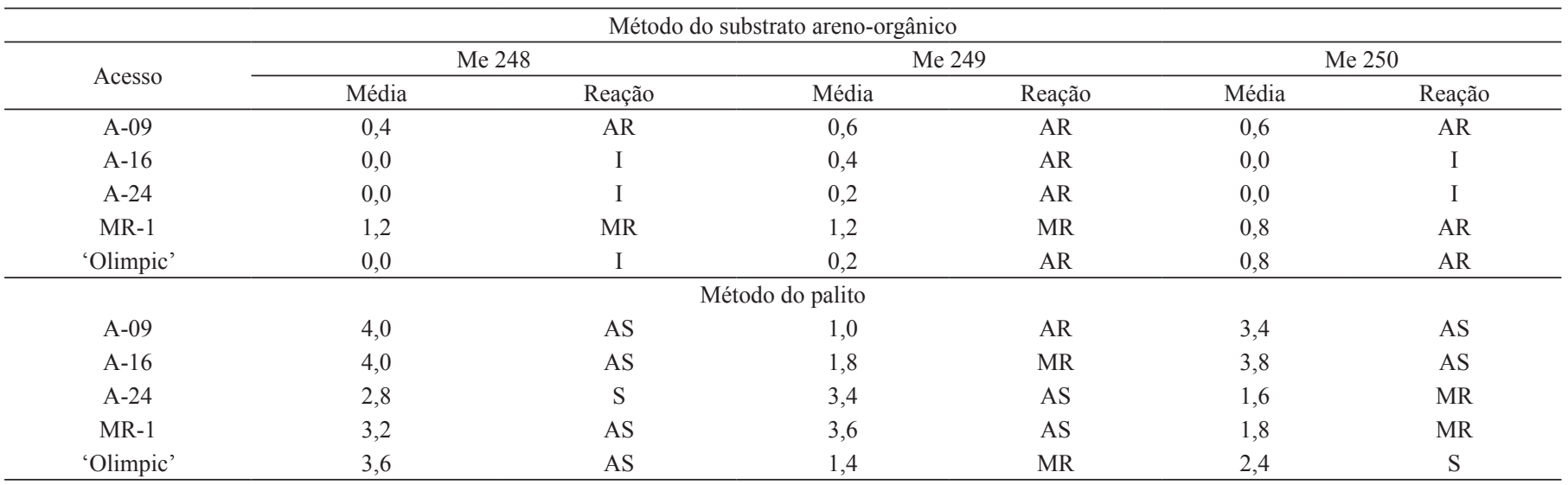

Significativo pelo teste de Kruskal-Wallis a 1\% de probabilidade. I: Imune [0,0]; AR: altamente resistente [0,1-1,0]; MR: medianamente resistente [1,1-2,0]; S: suscetível [2,1-3,0]; AS: altamente suscetível [3,1-4,0].

diferentes hospedeiros, como soja, sorgo, girassol, caupi, milho e trigo, e de duas amostras de solo de áreas virgens.

Os resultados mostraram que isolados mais divergentes, ou seja, mais virulentos, são oriundos de áreas com monocultura. Os resultados demonstram a existência de variabilidade genética entre os isolados brasileiros. Todavia, não existem informações entre os isolados coletados em meloeiro. Com relação à $R$. solani também trata-se de um fungo com uma população extremamente variável, inclusive com grupos de anastomose.

As principais vantagens do método do palito são as seguintes: a) uma quantidade relativamente constante de inóculo é colocada em contato íntimo com o tecido hospedeiro, reduzindo a possibilidade de contaminação com outro patógeno; b) conhecimento do tempo de inoculação, ou seja, contato do hospedeiro com o patógeno, permitindo o acompanhamento do progresso da doença e c) menor possibilidade de escape (19).

A principal crítica feita ao método do palito, bem como a outros métodos que introduzem o inóculo no caule da planta, é quanto à sua agressividade. Os pesquisadores argumentam que a aplicação do palito causa ruptura da parede celular, que pode ser um componente de resistência estrutural da planta, acarretando a não seleção de genótipos com um nível mediano de resistência (7). Com relação ao fungo $M$. phaseolina, sabe-se que o referido patógeno entra no tecido do hospedeiro dissolvendo a parede da célula por meio da secreção de toxinas ou enzimas.

A degradação da parede celular se deve à ação das enzimas polyglacturonase e celulase. O desenvolvimento de micélio intercelular e sua íntima associação com a parede celular no cortex são estritamente relacionados à intensidade de polyglacturonase (14).

Neste caso, indíviduos imunes ou altamente resistentes podem ter sido prejudicados pela agressividade do método do palito; todavia, o fungo pode penetrar por meio da pressão mecânica dos seus tubos germinativos, crescendo na membrana intacta com espessura de 5 a $10 \mu \mathrm{m}$.

Desta forma, apenas genótipos com espessura superiores a 10 $\mu \mathrm{m}$ seriam prejudicados. Outra crítica ao método do palito é por não simular o processo de infecção natural, que se inicia nas raízes e se espalha para o caule (7).

Entretanto, covém ressaltar que o método do palito tem sido amplamente utilizado em programas de melhoramento para avaliar a reação de genótipos a diversos patógenos, inclusive $R$. solani e $M$. phaseolina. $\mathrm{O}$ referido método foi usado com sucesso em culturas 
Tabela 4. Severidade, classes de reação e estimativas do coeficiente de correlação de Spearman entre os métodos palito de dente substrato arenoorgânico para a inoculação de três isolados de M. phaseolina em acessos de meloeiro. Mossoró-RN, 2013.

\begin{tabular}{|c|c|c|c|c|c|}
\hline \multirow[b]{2}{*}{ Isolado } & \multicolumn{2}{|c|}{ Severidade } & \multicolumn{2}{|c|}{ Classes de reação } & \multirow{2}{*}{$\begin{array}{c}\text { Estimativa } \\
(\mathrm{r})\end{array}$} \\
\hline & Palito & Areno-orgânico & Palito & Areno-orgânico & \\
\hline \multicolumn{6}{|c|}{ R. solani } \\
\hline M-242 & 2,2 & 0,3 & MR, S & MR, I & $0,08(\mathrm{p}>0,05)$ \\
\hline Me-244 & 2,6 & 0,2 & $\mathrm{AR}, \mathrm{S}$ & MR, I & $0,34(\mathrm{p}>0,05)$ \\
\hline \multicolumn{6}{|c|}{ M. phaseolina } \\
\hline $\mathrm{I}-250$ & 2,9 & 0,5 & $\mathrm{AR}, \mathrm{R}, \mathrm{MR}, \mathrm{S}$ & $\mathrm{AR}, \mathrm{R}$ & $0,11(p>0,05)$ \\
\hline
\end{tabular}

AR: altamente resistente; R: resistente; MR: medianamente resistente; S: suscetível; AS: altamente suscetível. $r_{\mathrm{s}}$ : Coeficiente de correlação de Spearman.

como a beterraba (16), sorgo (13), citros (26) e cenoura (23). No caso do meloeiro, o método foi utilizado com sucesso para avaliar a reação a Didymella bryoniae de diversas cucurbitáceas, candidatas a portaenxertos de melão rendilhado (12).

Embora o método da inoculação com substrato areno-orgânico no solo não tenha sido eficiente no presente estudo, há relatos da aplicação dessa metodologia para inocular patógenos radiculares (R. solani e $M$. phaseolina) (15;2). Em meloeiro, Michereff et al. (22) verificaram que a inoculação de $R$. solani com substrato areno-orgânico foi eficiente para selecionar cultivares comerciais de melão resistentes, no entanto, o método apresenta a desvantagem de não conhecer o período de incubação, o que exige maior período para o aparecimento dos sintomas e trata-se de uma avaliação mais trabalhosa, considerando a necessidade da retirada do solo das raízes (16), bem como a lavagem cuidadosa para observação dos sintomas.

O método do palito foi mais eficiente em discriminar os genótipos em classes distintas de resistência dependendo do isolado (Tabelas $2 \mathrm{e}$ 3). A discordância dos métodos pode ser verificada ao se observarem os valores reduzidos não significativos da correlação de Spearman (Tabela 4).

Observou-se também interação entre os fatores métodos e acessos, para todos os isolados (Tabela 1). A interação é caracterizada pelo comportamento diferencial dos acessos em função dos métodos de inoculação. Em outras palavras, há acessos que se comportam de maneira diferente em função do método de inoculação empregado, ou seja, a reação do acesso depende do método. Esse fato é muito importante no momento da escolha do método de inoculação a ser empregado para identificar materiais resistentes.

O método do palito é mais eficiente em discriminar acessos de melão resistentes e suscetíveis aos fungos $R$. solani e M. phaseolina.

O método do palito é mais eficiente em discriminar os isolados de R. solani e M. phaseolina quanto à agressividade.

\section{AGRADECIMENTOS}

Ao Cnpq, a Universidade Federal Rural do Semi-Árido - UFERSA e ao Grupo de Estudos em Recursos Genéticos e Melhoramento Vegetal da UFERSA.

\section{REFERÊNCIAS BIBLIOGRÁFICAS}

1. Almeida, A.M.R.; Abdelnoor, R.V.; Arias, C.A.A.; Carvalho, V.P.; Jacoud Filho, D. S.; Marin, S.R.R.; Benato, L.C.; Pinto, M.C.; CARVALHO, C.G.P. Genotypic diversity among brazilian isolates of Macrophomina phaseolina revealed by RAPD. Fitopatologia Brasileira, Brasília, v. 28, n.3, p. 279-285, 2003.

2. Ambrósio, M.M.Q.; Bueno, C.J.; Padovani, C.R.; Souza, N.L. Controle de fitopatógenos do solo com materiais vegetais associados à solarização. Summa phytopathologica. Botucatu, v. 34, n. 4, p. 354-358, 2008.

3. Andrade, D.E.G.T.; Michereff, S.J.; Biondi C.M.; Nascimento C.W.A.; Sales Júnior, R. Freqüência de fungos associados ao colapso do meloeiro e relação com características físicas, químicas e microbiológicas dos solos. Summa Phytopathologica, Botucatu, v. 31, n. 4, p. 327-333, 2005.

4. Bruton, B.D.; Wann, R. Podredumbre de carbón. In: Zitter, T.A.; Hopkins, D.L.; Thomas, C.E. (Eds.). Plagas y enfermedades de las cucurbitáceas. Madrid: Ediciones Mundi-Prensa, 2004. p. 9-11.

5. Bruton, B.D. Soilborn diseases in cucurbitaceae: pathogen virulence and host resistance. In: Mccreight, J. (Eds.). Cucurbitaceae 98. Alexandria: International Society of Horticultural Science, p. 143-166, 1998.

6. Costa, G.G. Reação de acessos de melão a Rhizoctonia solani. 2009. 29f. Monografia - (Graduação em Agronomia) - Departamento de Ciências Vegetais, Universidade Federal Rural do Semi-Àrido - UFERSA, Mossoró-RN, 2009.

7. Edmunds, L.K.; Voigt, R.L.; Carasso, F.M. Use of Arizona climate to induce charcoal rot in grain sorghum. Plant Disease Reporter, Saint Paul, v. 48, p. 300-302, 1964.

8. Fenille, R.; Souza, N.L. Efeitos de materiais orgânicos e da umidade do solo na patogenicidade de Rhizoctonia solani Kuhn GA-4 HGI ao feijoeiro. Pesquisa Agropecuária Brasileira, Brasília, v. 34, n. 10, p. 1959-1967, 1999.

9. Fita, A.; Picó, B.; Dias, R. C.S.; Nuez, F. 'Piel de Sapo' Breeding Lines Tolerant to Melon Vine Decline. Horts Cience, Alexandria, v. 44, n. 5, p. 1458-1460. 2009.

10. Garcia-Jimenez, J.; Armengol, J.; Sales, R.; Jordá, C.; Bruton. B.D. Fungal pathogens associated with melon plants collapse in Spain. EPPO Bulletin, Paris, v. 30, n. 2, p. 169-173, 2000.

11. Goulart, A.C.P. Efeito do tratamento de sementes de algodão com fungicidas no controle do tombamento de plântulas causado por Rhizoctonia solani. Fitopatologia Brasileira, Brasília, v. 27, n. 4, p. 399-402, 2002.

12. Ito, L.A.; Braz, L.T.; Camaro, M. Comparação entre métodos de inoculação de Didymella bryoniae para seleção de porta-enxertos de melão rendilhado. Horticultura Brasileira, Brasília, v. 30, n. 2 (Suplemento CD ROM), 2009.

13. Kavitha, T.R. Morphological and genetic variability and host resistance response of sorghum recombinant inbred lines (rils) to a virulent isolate of Macrophomina Phaseolina (Tassi) Goid. 2007. 62p. Thesis (Master of Science - Plant Pathology) - University of Agricultural Sciences, Dharwad, 2007.

14. Khan, S.N. Macrophomina phaseolina as causal agent for charcoal rot of sunflower. Mycopathology, Nova York, v. 5, n. 2, p. 111-118, 2007.

15. Lefèvre, A.F.; Souza, N.L. Determinação da temperatura letal para Rhi- 
zoctonia solani e Sclerotium rolfsii e efeito da solarização sobre a temperatura do solo. Summa Phytopathologica, Jaguariúna, v. 19, n. 2, p. 107-112, 1993.

16. Mahmoudi, S.B.; Ghashghaie, S. Reaction of sugar beet S1 lines and cultivars to different isolates of Macrophomina phaseolina and Rhizoctonia solani AG-2-2IIIB. Euphytica, Holanda, v. 175, n. 11, p. 10-16, 2012.

17. Maia, L.K.R.; Lima, R.E.M.; Lima, J.S. Importância do meloeiro e aspectos relacionados à resistência a Rhizoctonia solani. Enciclopédia Biosfera, Centro Científico Conhecer - Goiânia, v.9, n.17; p. 1609-1622, 2013.

18. Maia, L.K.R. Reação de acessos de meloeiro coletados no nordeste a Rhizoctonia solani 2011. 42f. Monografia - (Graduação em Agronomia) - Departamento de Ciências Vegetais, Universidade Federal Rural do Semi-Àrido - UFERSA, Mossoró-RN, 2011.

19. Medeiros, A.C. Reação de acessos de meloeiro à Macrophomina phaseolina utilizando diferentes métodos de inoculação. 2013. 47f.: il. Dissertação (Mestrado em Fitotecnia) - Universidade Federal Rural do Semiárido. Pró-Reitoria de Pesquisa e Pós-Graduação.

20. Michereff Filho, M.; Michereff, S.J.; Silva, E.B.; Andrade, D.E.G.T.; AntuneS Sobrinho, S.; Noronha, M. A.; Mariano, R. L. R. Influência de tipos de solo do estado de Pernambuco na intensidade da doença induzida por Rhizoctonia solani em feijoeiro. Fitopatologia Brasileira, Brasília, v. 21, n. 1, p. 19-25, 1996.

21. Michereff, S.J.; Andrade, D.E.G.T.; Sales Júnior, R. Reaction of melon genotypes to Rhizoctonia solani. Horticultura Brasileira, Brasília, v. 26, n. 3, p. 401-404, 2008.

22. Noronha, M.A.; Michereff, S.J.; Mariano R.L.R. Efeito do tratamento de sementes de caupi com Bacillus subtilis no controle de Rhizoctonia solani. Fitopatologia Brasileira, Brasília, v. 20, n. 2, p. 174-178, 1995.

23. Pryor, B.M.; Davis, R.M.; Gilbertson, R.L.A. Toothpick Inoculation Method for Evaluating Carrot Cultivars for Resistance to Alternaria radicina. HortScience, Alexandria, v. 35, n. 6, p. 1099-1102, 2000.

24. Salari, M.; Panjehkeh, N.; NasirpooR, Z.; Abkhoo, J. Reaction of melon (Cucumis melo L.) cultivars to soil-borne plant pathogenic fungi in Iran. African Journal of Biotechnology, Nairob: Academic Journals, v.11, n.87, p.15324-15329, 2012.

25. Shan, D.A.; Madden, L.V. Nonparametric Analysis of Ordinal Data in Designed Factorial Experiments. Phytopathology, Saint Paul, v. 9, n. 1, p. 33-43. 2004.

26. SIVIERO, A.; Furtado, E.L.; Boava, L.P.; Barbasso, D.V.; MACHADO, M.A. Avaliação de métodos de inoculação de Phytophthora parasita em plântulas e plantas jovens de citrus. Fitopatologia Brasileira, Brasília, v. 27 , n. 6 , p. 574-580, 2002.

27. Tolêdo-Souza, E.D.; Costa, E.J.L.S. Métodos de inoculação de plântulas de feijoeiro para avaliação de germoplasma quanto a resistência a Sclerotinia sclerotiorum (Lib.) De Bary. Pesquisa Agropecuária Tropical, Goiânia, v. 2, n. 33, p. 57-63, 2003.

28. Verzignassi, J.R.; Vida J.B.; Gasparotto, F.; Cortez, G.L.S.; Lorenzetti, E.R.; Faria, G.S.; Tessmann, D.J.; Severino, J.J. 2004. Método do palito para inoculação de Didymella bryoniae em melão nobre e pepino "japonês". Fitopatologia Brasileira, Brasília, v. 29 (suplemento), p. 5154.

29. Yorinori, J.T. Cancro da haste da soja: epidemiologia e controle. Londrina: Embrapa Soja. 1996. 75p. (Embrapa Soja. Circular Técnica, 14). 